\title{
Experimental and numerical study of upstream slope stability in an earth dam reservoir under rapid drawdown conditions
}

Estudio experimental y numérico de la estabilidad de la pendiente aguas arriba en un embalse de presas de tierra en condiciones de extracción rápida

Author:

Mansour Pakmanesh ${ }^{1}$

Seyed Habib Mousavi Jahromi2 ${ }^{2}$

Amir Khosrojerdi ${ }^{3}$

Hossein Hassanpour Darvishi ${ }^{4}$

Hossein Babazadeh ${ }^{5}$

\section{SCIENTIFIC RESEARCH}

How to cite this paper:

Pakmanesh M., Mousavi Jahromi S., Khosrojerdi A., Hassanpour Darvishi H. and Babazadeh H., Experimental and numerical study of upstream slope stability in an earth dam reservoir under rapid drawdown conditions, Iran. Innovaciencia 2020 ; 8 (1): 1 -15. DOI : http :// dx .doi .org / $10.15649 /$ 2346075X.1006

\section{Reception date:}

Received: 01 May 2020

Accepted: 01 August 2020

Published: 01 December 2020

\section{ABSTRACT}

Introduction: The rapid drawdown of the dam reservoir is one of the most common situations occurring in the lifetime of a dam. For this reason, one of the main factors in the design of the upstream slope is the rapid drainage of the reservoir. In this case, the upstream slope is in a critical condition and the slope may be unstable. When the water surface in the reservoir is drawdown suddenly, the water level in the dam body does not decrease at the same time as the reservoir water level. Materials and Methods: The analysis of seepage from the earth dam body and calculation of the water loss play an important role in calculating the amount of pore water pressure, and, consequently, the stability analysis of the dam body. In addition, any seepage analysis is dependent on the hydraulic properties of the dam materials. In order to investigate the effect of hydraulic conductivity on the rapid drawdown of water level and the seepage, an experimental model was constructed of an earth dam. Results and discussion: By accurate measurement of hydraulic parameters of the materials in saturated and unsaturated media, the flow through this model was modeled using a disk penetrometer by seep/w software. The results were then compared with the observed data.

Keywords:

Slope Stability, rapid drawdown, earth dam, drainage prediction, seep/w.

1 PhD Student, Department of Water Science and Engineering, Science and Research Branch, Islamic Azad University, Tehran, Iran

2* Professor, Department of Water Science and Engineering, Science and Research Branch, Islamic Azad University, Tehran, Iran.

Corresponding author: Seyed Habib Mousavi Jahromi Email: h-mousavi@srbiau.ac.ir

3 Assistant Professor, Department of Water Science and Engineering, Science and Research Branch, Islamic Azad University, Tehran, Iran.

4 Associate Professor, Department of Civil Engineering - Engineering and Managment of Water Resources, Islamic Azad University, Shahr-e-Qods Branch, Tehran, Iran

5 Associate Professor, Department of Water Science and Engineering, Science and Research Branch, Islamic Azad University Tehran, Iran 


\section{INTRODUCTION}

Distribution of moisture in porous media in the presence of a rapid drawdown in water levels and steady and unsteady seepages is important in many issues, such as seepage from the earth dam, and the interaction of surface water with groundwater, water seepage and loss in transmission channel, various environmental issues, and dispersion of the contaminant ${ }^{[1]}$. Many researchers have focused on the unconfined seepage with an unknown free surface and many methods have been recently presented for analyzing such issues. For example, the unsteady seepage flux affected by rainfall and surface water fluctuations have been investigated using an unsaturated-semi-saturated seepage model based on the two-phase flow theory of air-water in a porous medium [1]. The SUTRA model (finite element model of saturation-unsaturated flow dependent on the fluid density) was modified for groundwater flux affected by cyclical fluctuations of boundary conditions, such as wet and dry periods [2-3] solved the seepage problems with free flow through a solution called the so-called high pressure problem using the single-axis bridge function (OHS) 0 and 1 . In recent years, it has improved significantly with modifications to the unconstrained condition [4-5] proposed an optimal analytic model of slope stability analysis of earth-rockfill dams by employing modified genetic algorithm (MGA) to search for the slip surface with respect to shear failure criteria of the nonlinear Unified Strength Theory without presupposing the shape of slip surface. Based on their results, MGA is a highly efficient, simple, and good performance of fault-tolerance algorithm. [6] numerically investigated the reliability of slope stability in an erath dam under rapid drawdown condition.

Slope stability was conducted by using safety factor as estimated by the Bishop's simplified relation. The results revealed that the factor of safety varied mainly according to two parameters, namely the coefficient of friction and the cohesion. Finally, they recommended one formula to avoid the possibility of failure related to slope stability. [7] conducted stochastic seepage and probabilistic analyses of slope stability of earth-fill dam. Slope stability calculations carried out using five different limit equilibrium methods. Afterwards, the most and least ones of the methods used were presented in terms of reliability index. Moreover, the probabilistic analysis was performed with deterministic seepage flow. Also, the impact of sampling type of soil parameters in probabilistic stability analysis was evaluated.

Many of developed models are dependent on pressure or hydraulic load. As a result, in these models and numerical methods, due to the appearance of the capillary, it is not possible to accurately determine the air-water interface. Also, due to the dramatic changes in the soil saturation near this surface, it is difficult to determine the exact position of the phreatic level [8]. Therefore, to determine the exact position of the seepage level and the phreatic line, it is necessary to determine the hydraulic conductivity of the porous medium in unsaturated state. In fact, the limitation of the application of the seepage analysis models is related to the determination of the hydraulic properties of the porous medium; especially the changes in moisture and permeability of the porous medium in non-saturated conditions [9]. Hydraulic properties of soil materials through direct experimental methods as well as indirect methods including regression methods or empirical models based on some extractable soil characteristics [10].

Disk diffusion penetrometer is a precise method for evaluating the soil hydraulic parameters in situ. The main advantage of this penetrometer is minimum distribution of the soil surface during the measurement. Various characteristics of soil hydraulic parameters can be measured using disk diffusion penetrometer [11-12].

In this research, the effect of unsaturated hydraulic properties of soil materials on unconfined seepage through the earth dam body was investigated. Accordingly, the position of the seepage line, the distribution of water pressure, and the amount of flow through the body of the homogeneous earth dam were studied. 


\section{MATERIALS AND METHODS}

\subsection{Experimental Model}

In order to investigate the water drawdown in the earth dams, an experimental model of homogeneous earth model with a height of $70 \mathrm{~cm}$ was constructed in a symmetrical shape relative to the dam axis (Figure 1). To investigate the seepage line and pore water pressure of the dam body, 80 piezometers in three rows with a bottom-up numbering of 5, 15 and $30 \mathrm{~cm}$ from the impervious bottom and at different horizontal distances of 5 and $10 \mathrm{~cm}$.

The piezoelectric densities in the downstream body were higher than the upper part. The reason for this selection is the more intense changes in the seepage surface in the lower half of the dam body. Figure 2 shows a schematic view of the model, with the position of the piezometers mounted on the body of the model. As can be seen in Fig. 2, the secondrow piezometers (middle piezometers) are located in the downstream body, and only two piezometers of this row are located in the upstream body.

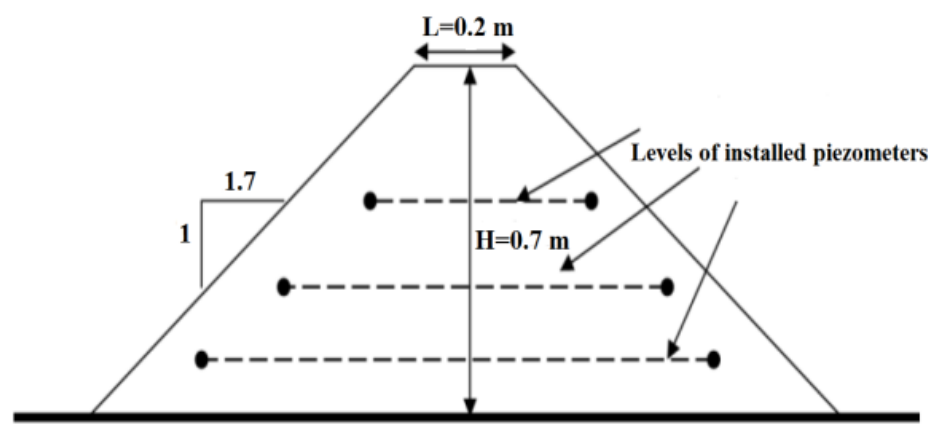

Figure 1. Geometry and specification of the experimental model

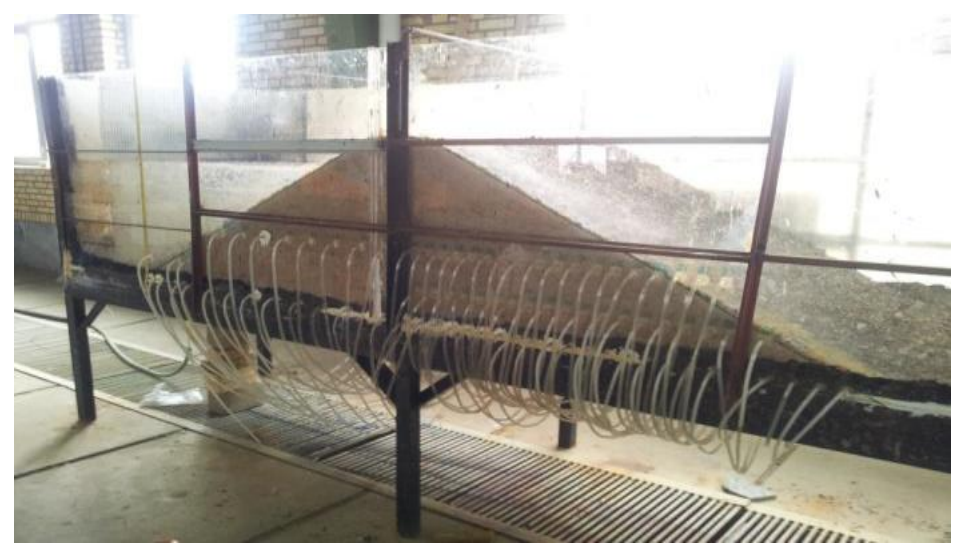

Figure 2. The experimental model of the earth dam and the piezometers mounted in the body of the model (bottom-up photograph)

In the bottom of the model, a rough surface plate was used in order to reduce the seepage flux in the contact area of the soil with the model body. In addition, in order to reduce the seepage through the side walls of the model and the soil, a fine-grain sand layer was glued to the surface of the side walls. This layer reduces the seepage flux and increases the friction between the soil and the wall surface, and also prevents the soil separation phenomenon and lateral plates [13]. The side walls were made of plexiglass and other parts were made of steel. In the upstream and downstream areas of the earth dam, water reservoirs with the ability of water level were considered to study unsteady seepage conditions in the model. 


\subsection{Experimental study}

In every seepage phenomenon, in addition to geometry and governing boundary conditions, the characteristics of materials play a major role in the flow pattern. For physical model of the earth dam, sand materials containing small percentage of silt was used. Figure 3 shows the grain size distribution of the material of the earth dam. The reason for the use of such materials is the rapid response of these soils to the changes in the boundary conditions and, consequently, the saving the time. To construct the earth dam body, the soil layers were poured into a thickness of $5 \mathrm{~cm}$ and were condensed with a manual roller.

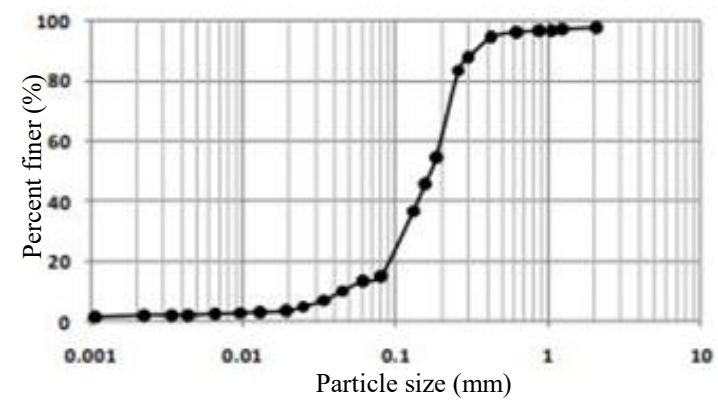

Figure 3. Grain size distribution of the dam body

Water drawdown experiment under various water heads in the upstream of 10 to $60 \mathrm{~cm}$ were conducted as stable and unstable in the form of reducing the reservoir water level with $10 \mathrm{~cm}$ water level steps. The time interval of reduction in the water surface to the desired level was considered about $10 \mathrm{~min}$, and the equilibrium time and the starting a steady flow was controlled based on changes in the surface water of the piezometers. After stabilizing the steady conditions, the water level in the piezometers was fixed. In order to investigate the effect of hydraulic conductivity on unsteady seepage analysis (or transition), seepage experiments were investigated with variable boundary conditions. Since in the stability analysis of the earth dams unstable condition is generally considered for the rapid drawdown of the water surface, unstable seepage experiments were also carried out. A rapid drawdown in reservoir water level in unstable seepage analysis was done in intervals of $10 \mathrm{~cm}$ in every $10 \mathrm{~min}$. A total of 4 different steps of unstable seepage analysis were performed. The start time of each step of the unstable tests was the previous step after reaching the equilibrium.

In addition, the seepage flux passed through the body of the earth dam was measured in the output section of the laboratory model. Considering that the main objective of this study is to investigate the effect of hydraulic parameters of body materials on the seepage analysis through the dam's body, after preparing disturbed samples, the hydraulic properties of the materials, including the moisture characteristic curve and the hydraulic conductivity function, were determined by the laboratory method. In order to determine the moisture characteristic curve, the pressure plate test was conducted with the pressures up to maximum $3 \mathrm{~atm}$ suction. The moisture characteristic curve resulting from the three replications of this test on the body material of the model is shown in figure 4. The permeability of the body materials in the vertical direction was determined using two methods of constant load for determining the saturated hydraulic conductivity and the tension infiltrometer for unsaturated hydraulic conductivity. The saturated hydraulic conductivity obtained from three replicates of the constant load test was $6.41 \mathrm{~cm} / \mathrm{s}$. In order to determine the unsaturated permeability in the vertical direction at the time of rapid drawdown, an intrusive penetration device with a disk diameter of $20 \mathrm{~cm}$ was used. Permeability measurement experiments were carried out after the completion of seepage tests and at a depth of about $20 \mathrm{~cm}$ below the dam crest.

For this purpose, the surface was carefully flattened after removing a layer with the thickness of $20 \mathrm{~cm}$ 
from the dam surface and before doing the test. Then, a thin layer of sand, with a thickness of $2 \mathrm{~mm}$ (or less), with a particle size of about 100 $\mu \mathrm{m}$, was poured over the soil surface to ensure proper hydraulic contact between the permeation disc and the soil surface. Figure 5 shows an image of the penetration device used on the crest of the dam. Disk permeability tests were performed in the matric potentials of $-20,-17,-10,-3$ and 0 $\mathrm{cm}$ starting from the minimum pressure $(-20 \mathrm{~cm})$. For each experiment, the cumulative penetration was recorded to obtain stable conditions at $1 \mathrm{~min}$ intervals. Totally, the stable penetration was obtained for the minimum pressure $(-20 \mathrm{~cm})$ about $50 \mathrm{~min}$ after beginning the test. For higher pressures to the saturation conditions (compressive height of $\mathrm{cm}$ ), the time to reach the constant penetration speed was reduced.

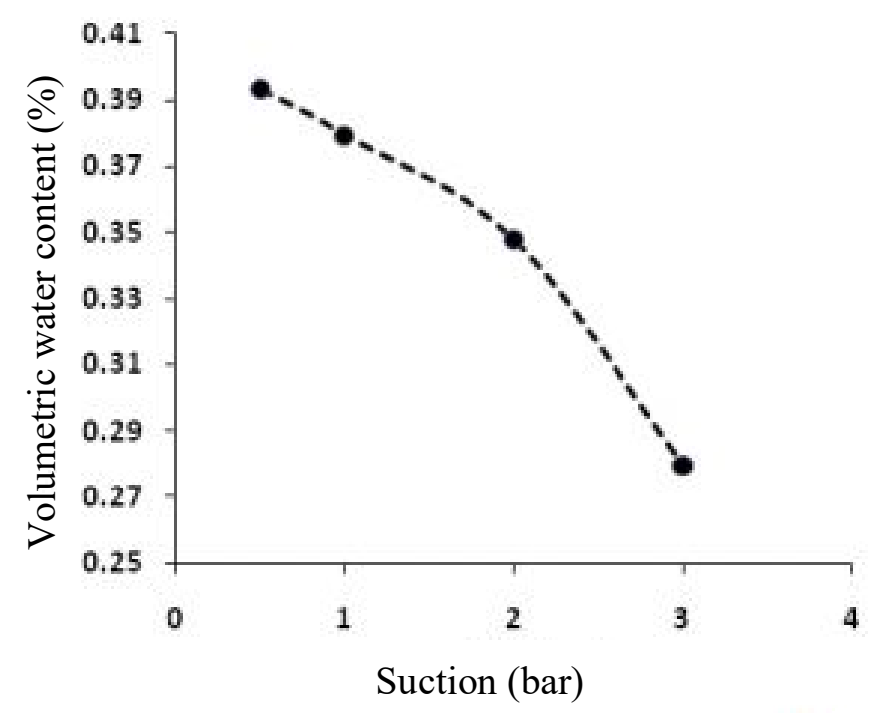

Figure 4. Moisture characteristic curve of the body materials of the experimental model homogeneous dam

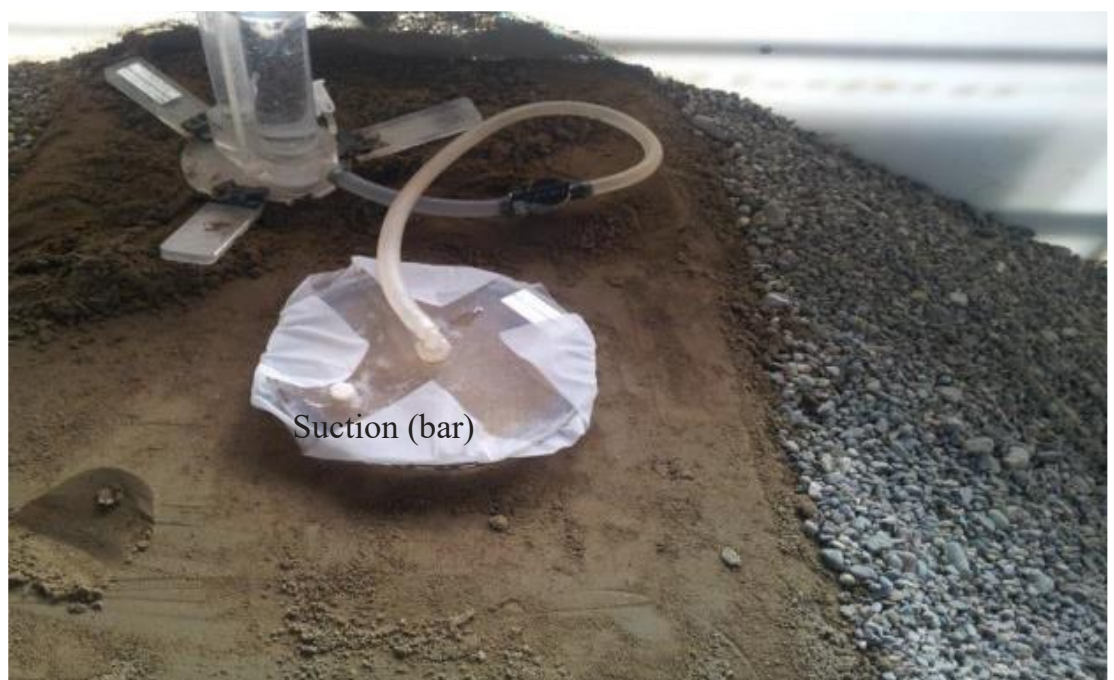

Figure 5. Suction system for disk installed on the body of the dam to measure unsaturated hydraulic conductivity

Using the Logsdon and Jaynes's [14] method, the unsaturated hydraulic conductivity values of the body of the physical model were calculated from the values of three-dimensional stable permeability in different matrix potentials. This method is based on the approximate solution of the Wooding's [15] 
equation to create a rapid drawdown in water level and the infinite stable permeability of $\mathrm{Q}(\mathrm{h})$ from a shallow circular water source and Gardner's [16] hydraulic conductivity exponential function, as follows:

$$
\frac{Q(h)}{\pi R^{2}}=K_{S} \exp (\alpha h)+\frac{\left[4 K_{S} \exp (\square \mathrm{h})\right]}{\pi R \alpha}
$$

Where $\mathrm{Q}(\mathrm{h})$ is the stable permeability $\left[\mathrm{L}^{3} \mathrm{~T}^{-1}\right]$ under the matrix potential of $h, R$ is the disk diffuser [L], a Gardner index for size distribution of the soil porosity $\left[\mathrm{L}^{-1}\right]$, and $\mathrm{K}_{\mathrm{s}}$ is the saturated hydraulic conductivity $\left[\mathrm{LT}^{-1}\right]$.

According to Logsdon and Jaynes [14] method, the fitting parameters of $\mathrm{a}$ and $\mathrm{K}_{\mathrm{s}}$ were obtained by nonlinear regression of permeability rates versus matrix potentials values; then, the values of $\mathrm{K}$ were determined for other matric potentials using the exponential function [16]. This function can be represented as follows:

$$
K=K_{S} \exp (\alpha h)
$$

Where $\mathrm{K}_{\mathrm{s}}$ is the saturated hydraulic conductivity and $\mathrm{K}$ is the hydraulic conductivity at the matrix potential of $\mathrm{h}$. In this study, the estimated hydraulic conductivity function is shown in Eq. 3:

$$
K=5.676 \exp (0.199 h)
$$

Where $\mathrm{K}$ is the hydraulic conductivity $(\mathrm{cm} / \mathrm{hr})$ and $\mathrm{h}$ is in $\mathrm{cm}$. However, the maximum suction capacity with this device is less than $1 \mathrm{~atm}$. According to the type of materials, the applied suction range is sufficient and the trend of the changes in resulting curve confirms this point. Figure 6 shows the hydraulic function curve of the body materials of the physical model.

\subsection{Governing equations}

The relationship between the water flow in the porous medium and the seepage in a two-dimensional (4) state is as follows: $\frac{\partial}{\partial x}\left(k_{x} \frac{\partial h}{\partial x}\right)+\frac{\partial}{\partial y}\left(k_{u} \frac{\partial H}{\partial y}\right)+Q=\frac{\partial \theta}{\partial t}$

In which $\mathrm{H}$ is the total energy, $\mathrm{k}_{\mathrm{x}}$ is the permeability in direction $\mathrm{x}, \mathrm{k}_{\mathrm{y}}$ is the permeability in direction $\mathrm{y}, \mathrm{Q}$ is the flux introduced from the boundaries of the volumetric moisture content, $\Theta$ is the volumetric water content, and $t$ is the time.

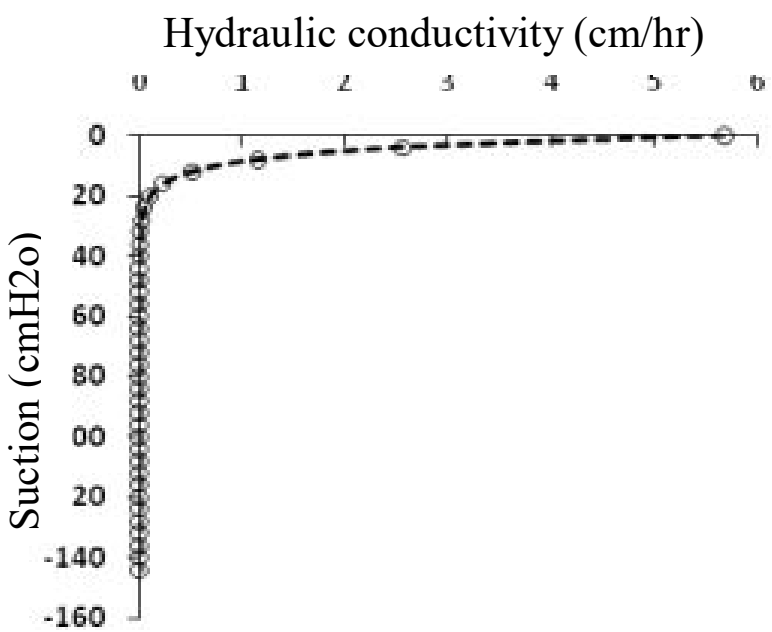

Figure 6. Variation of the permeability of the materials in different suctions

Volumetric moistures depend on changes in the state of tension and physical properties of the soil. The state of tension variables are expressed as two terms of ( $\sigma$-uw) and (ua-uw), in which $\sigma$ is the total stress and $u_{a}$ and $u_{w}$ are air and pore pressure, respectively. Since in the saturated or unsaturated part of the dam body the total stress and pore pressure are constant, the changes volumetric moisture is proportional to changes in the pore or suction pressures. This pressure is, in turn, a part of the total energy $(\mathrm{H})$ in Eq. 4. This equation is usually solved by the numerical methods of finite element or finite difference.

In this study, the seep/w-2007 software was used for solving the Eq. 4 in the geometry of the laboratory model. The numerical basis of this software is the finite element method. In this study, triangular and quad elements were used with 3 and 4 Goss integral points and non-systematic, as shown in Figure 7. 


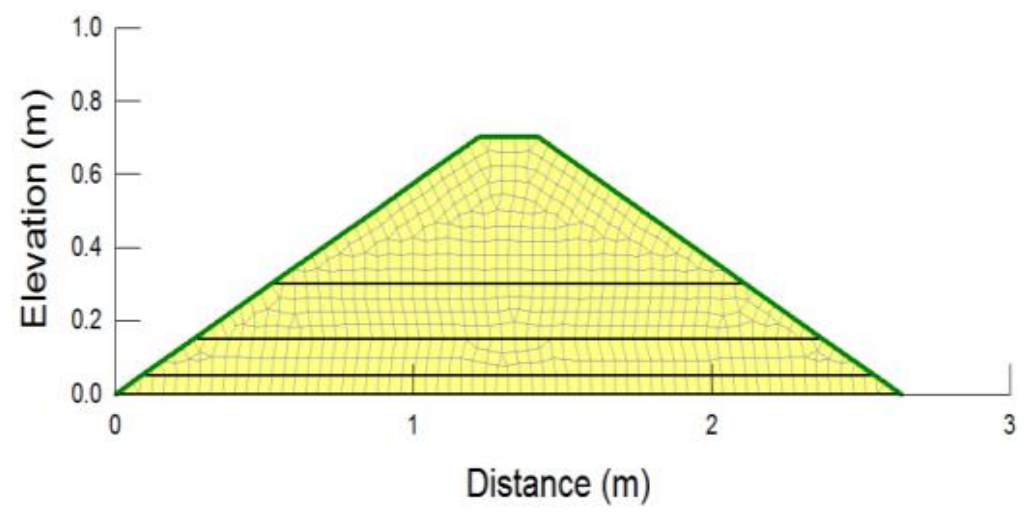

Figure 7. A view of mesh used based on triangular and quad elements.

\section{RESULTS AND DISCUSSION}

Since the purpose of this study was to investigate the effect of transfer functions including hydraulic conductivity and moisture characteristic curve in numerical modeling of the rapid water drawdown and seepage in the earth dams in steady and unsteady states, the results were investigated according to different scenarios and based on the combination of different conditions and functions.

\subsection{Validation of the Model}

Given that the earth dam body was made as $5-\mathrm{cm}$ layers, the heterogeneity in the hydraulic conductivity parameter of the body was obvious. In order to determine the ratio of horizontal to the vertical hydraulic conductivities, according to the experimental data, the rapid drawdown of the dam body with maximum water level in the upstream (60 $\mathrm{cm}$ ) and in steady and unsteady states, the model was calibrated based on the uniformity of the hydraulic conductivity of the earth dam body.

The reason for choosing this level was the maximum contribution of the dam materials to the flow through them. Because in the steady state conditions of the right side of the Eq. 4 is equal, the moisture characteristic curve does not affect the results, and only the hydraulic conductivity value is the effective parameter. Calibration of the model was performed by comparing the different values of the piezometric pressure recorded in the experimental and numerical model with the amount of seepage passing through the dam body. The final result of this study showed that the best conformance of the results of the model and observational data was obtained when the horizontal hydraulic conductivity was 5.7 $\mathrm{cm} / \mathrm{h}$ and the ratio of vertical to the horizontal hydraulic conductivities of the dam body was equal to 0.7. Figure 8 shows a comparison of the piezometric pressures obtained from model analysis with observational data in three different levels for maximum reservoir water level. 


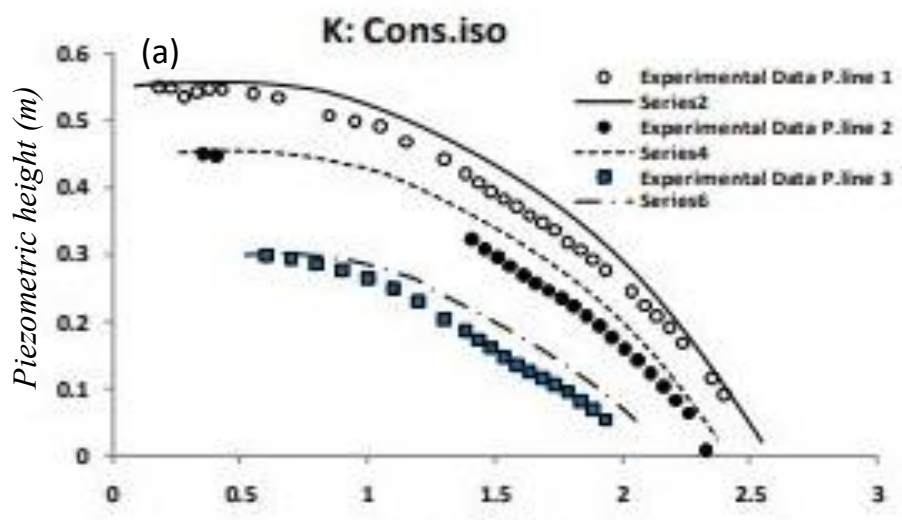

Distance from the hell of the dam (m)
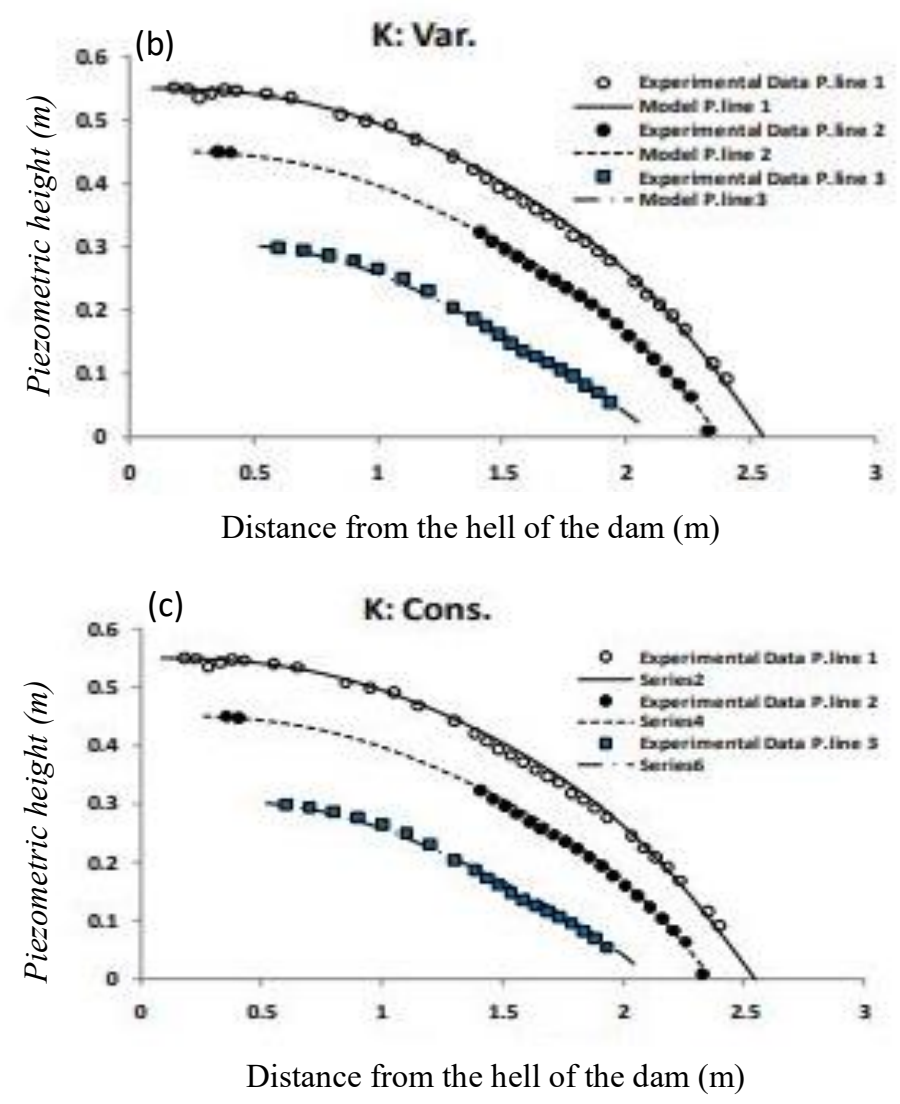

Figure 8. Comparison of measured piezometric data and modeled results. Note: Prior to calibration, using a saturated hydraulic conductivity of Penetration experiments on the soil sample are also considered (a) and after calibration based on three rows of piezometers installed in the laboratory model and non-hydraulic conductivity Saturation (b) and saturation (c) in a non-coercive state.

\subsection{Steady State Seepage}

In order to investigate the effect of hydraulic conductivity function on the rapid drawdown in water level, the seepage through the dam body of homogeneous earth dam was constructed. The variations of pressure in three different levels were selected according to the position of the piezometers in three rows as the representative of the study. In the experiment with higher phreatic level than the position of the second or third rows of the piezometers (positive pressure head), the data of each row were separately used. 


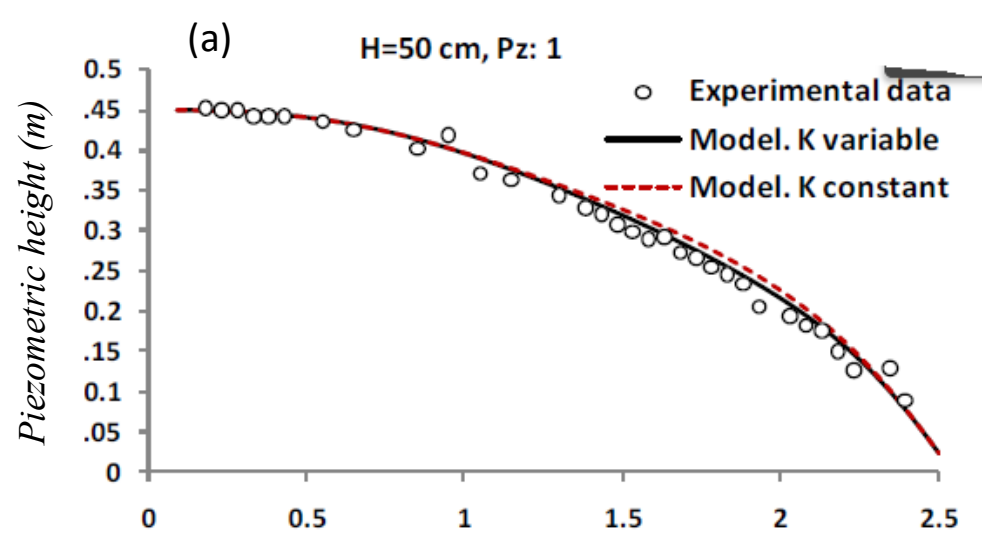

Distance from the hell of the dam (m)

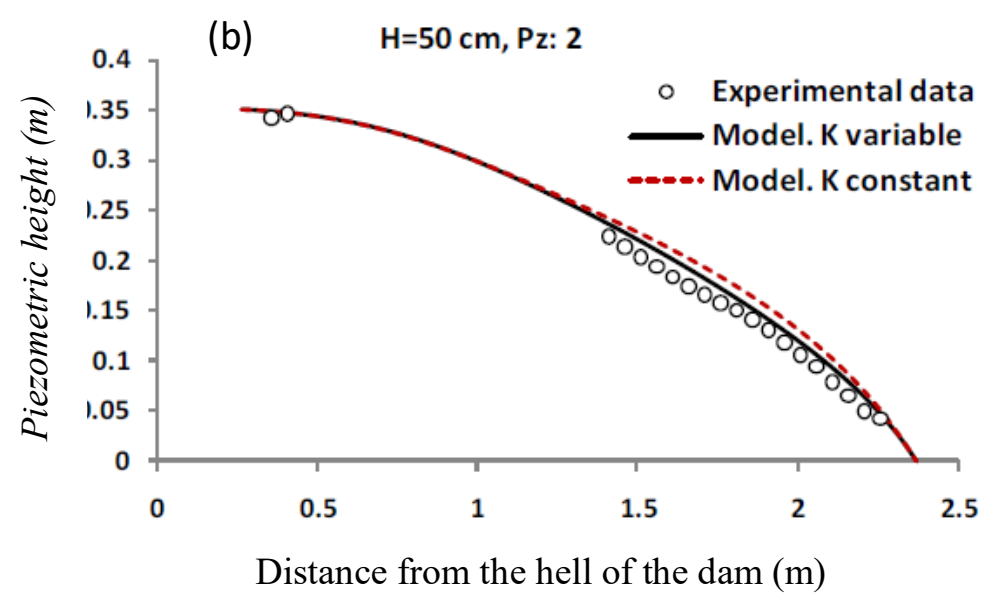

Figure 9._Comparison of pressure load in first (a) and second (b) row piezoelectric sensors with experimental data with saturated and unsaturated hydraulic conductivity in the state reservoir water level of $50 \mathrm{~cm}$.

Figure 9 shows the results of a comparison of the phreatic surface obtained from experimental data and the numerical results of two different states of applying fixed and variable hydraulic conductivity in a $50 \mathrm{~cm}$ water level in the reservoir. Figure $9 \mathrm{a}$ is related to first row piezometers located at the depth $5 \mathrm{~cm}$ from the impervious bottom of the model. Comparison of the results of Figure 9 shows that there is a difference between the downstream and seepage areas of the experimental and numerical data. This difference for saturated hydraulic conductivity is high. For this state (the water level of $50 \mathrm{~cm}$ reservoir), the comparison of the data of the second row piezometers (water level of $15 \mathrm{~cm}$ from the bottom) in Figure 9b shows that the difference between the results of the model in both the variable saturated and non-saturated hydraulic conductivities is increased to downstream. 

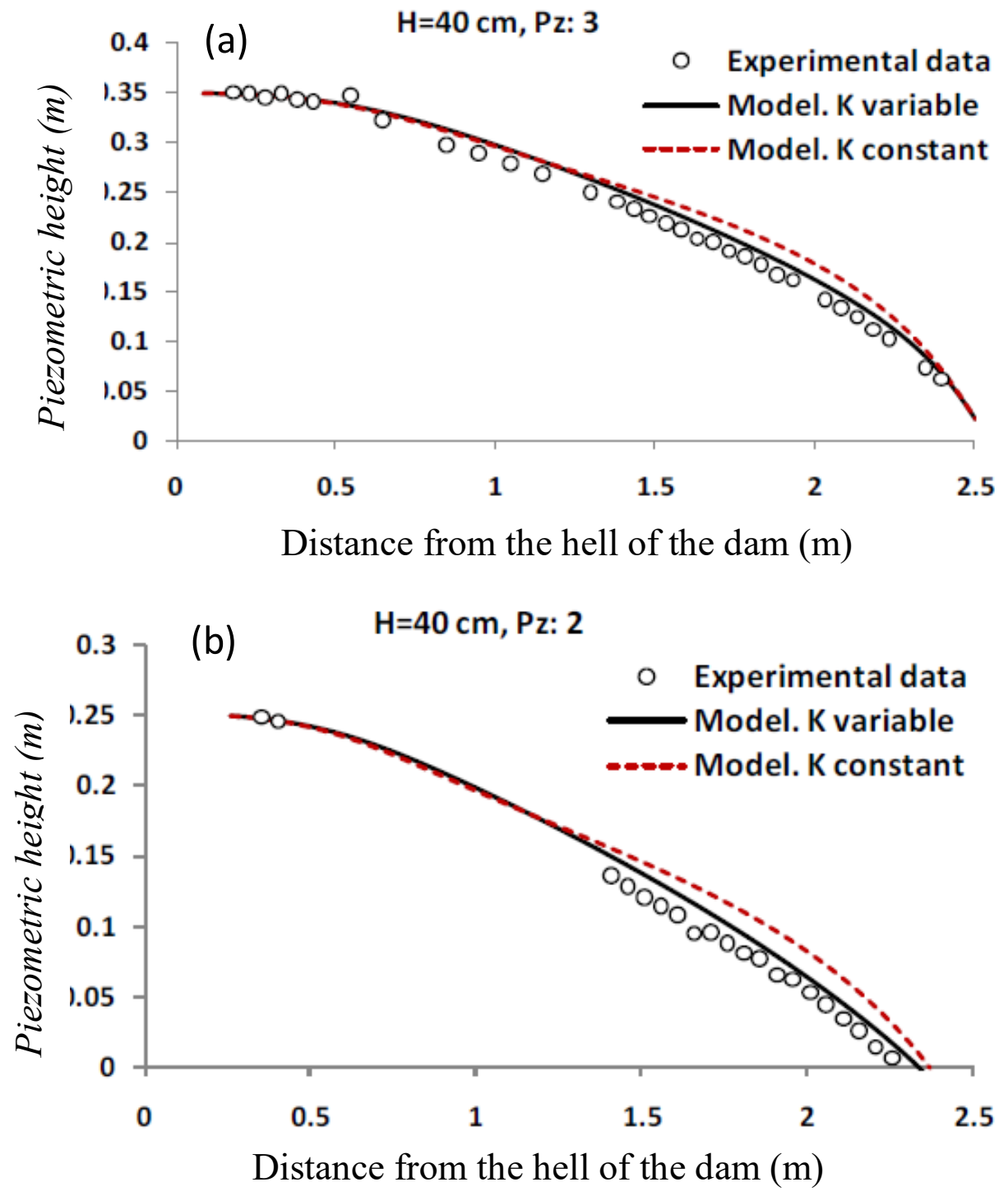

Figure 10. Comparison of the pressure load in the piezoelectric cells of the first (a) and second (b) row. Laboratory data with saturated and unsaturated hydraulic conductivity in the state reservoir water level of 40 $\mathrm{cm}$.

The experimental data is directly related to the reservoir water level and the distance between the phreatic surface and the position of the piezometers, so that as the water level in the reservoir decreases, the difference between the results of the numerical analysis and the measured data also increases. In addition, by decreasing distance between the phreatic surface and piezometer level this difference becomes more pronounced. 


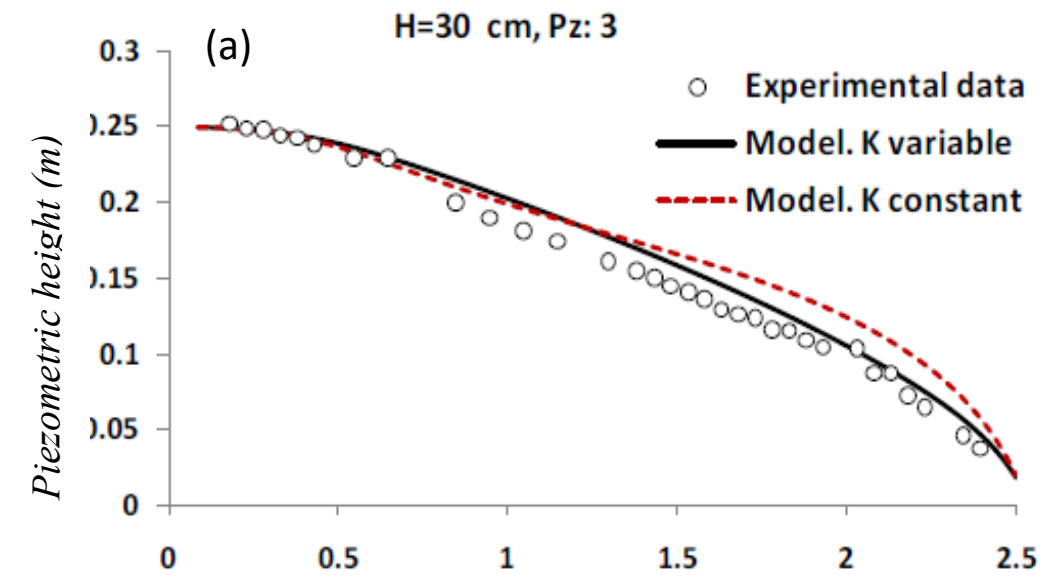

Distance from the hell of the dam (m)

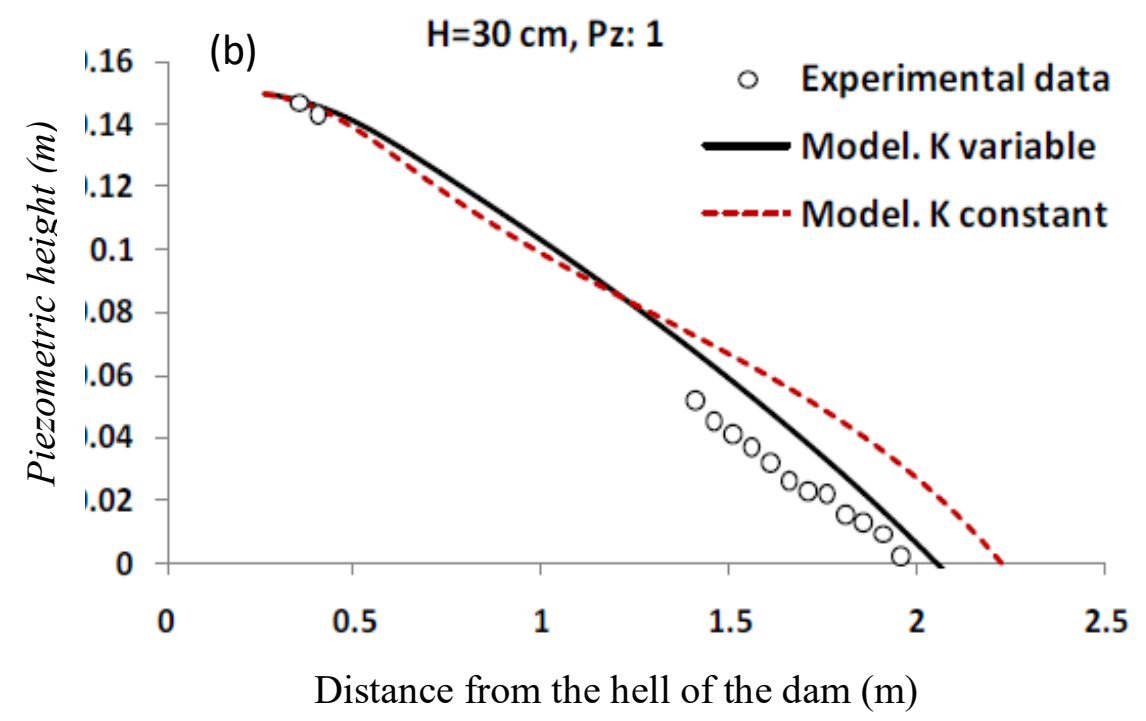

Figure 11. Comparison of the pressure load in the piezoelectric cells of the first row (a) and second row (b). Laboratory data with saturated and unsaturated hydraulic conductivity in the state reservoir water level of $30 \mathrm{~cm}$.

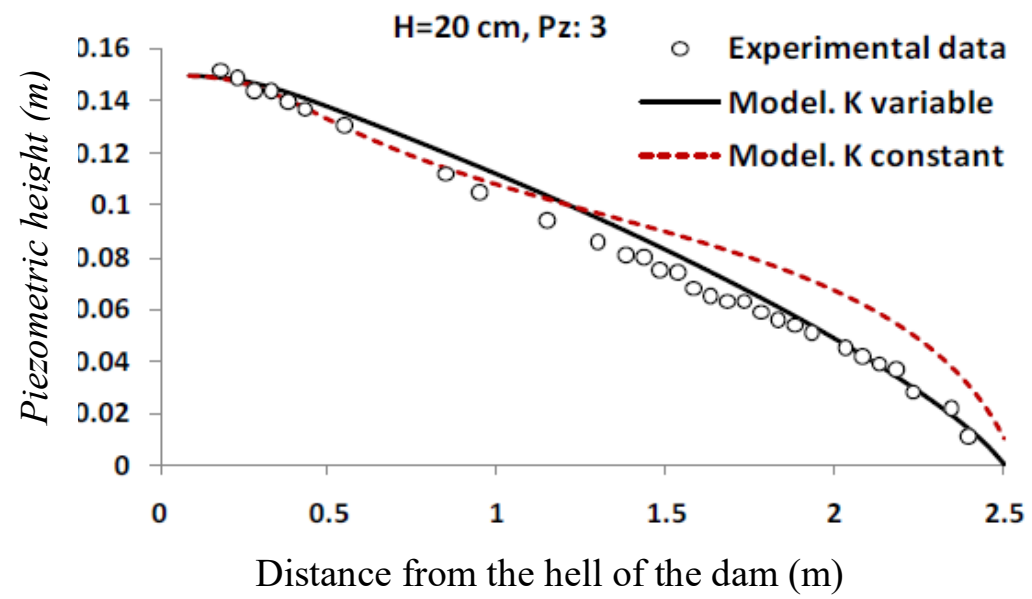

Figure 12._Comparison of pressure load in third row piezoelectric sensors with laboratory data with saturated and unsaturated hydraulic conductivity in the state reservoir water level of $20 \mathrm{~cm}$. 
Another remarkable point of this study is that the results of numerical analysis based on unsaturated hydraulic conductivity are more logical. Also, the difference between the results of the model and the observational data is increased with approaching the seepage surface and downstream of the dam body. The results of this study showed that for constant hydraulic conductivity (saturation) the piezometric pressure changes after crossing a turning point is significantly different from the observational data. However, in the upstream parts close to the reservoir, due to the proximity to the defined boundary conditions (Dirichlet or first-type boundary condition), the consistency of the model results with observational data is appropriate. In addition, in both states the application of variable unsaturated hydraulic conductivity and constant saturated hydraulic conductivity, the model is overestimated the pore water pressures and this difference is increased to the downstream. This is due to the uncertainty of the boundary geometry inside and downstream of the dam body before numerical solution. Another reason is related to the method of model calibration, because the calibration is based on the maximum water level in the reservoir. As a result, this situation deviates from the calibrated condition by reducing the water level in the reservoir.

It is worth considering that in the calibration graphs (Figure 8), the difference between the data of upper piezometers and the results of the model is high, and this is due to various factors, such as the hydraulic gradient near the phreatic surface. In any way, the comparison of the obtained results confirms that the unsaturated hydraulic conductivity provides more accurate and realistic results than the application of saturated hydraulic conductivity. In order to investigate the effect of saturated and unsaturated hydraulic conductivities on the numerical analysis of the seepage through the dam body, the seepage values obtained from the numerical analysis of each of the studied states and observational data were compared. Figure 13 shows the results of these comparisons. As can be seen in Figure 13, in the case of using the unsaturated hydraulic conductivity, a fairly well agreement between observed data and modeled results are obtained. When using constant hydraulic conductivity equal to the saturated hydraulic conductivity, the model results provide larger values than the observational data. As shown in Figure 13, the data corresponding to head of $60 \mathrm{~cm}$ related to both modes of hydraulic conductivity is consistent, which this is the calibration point of the model.

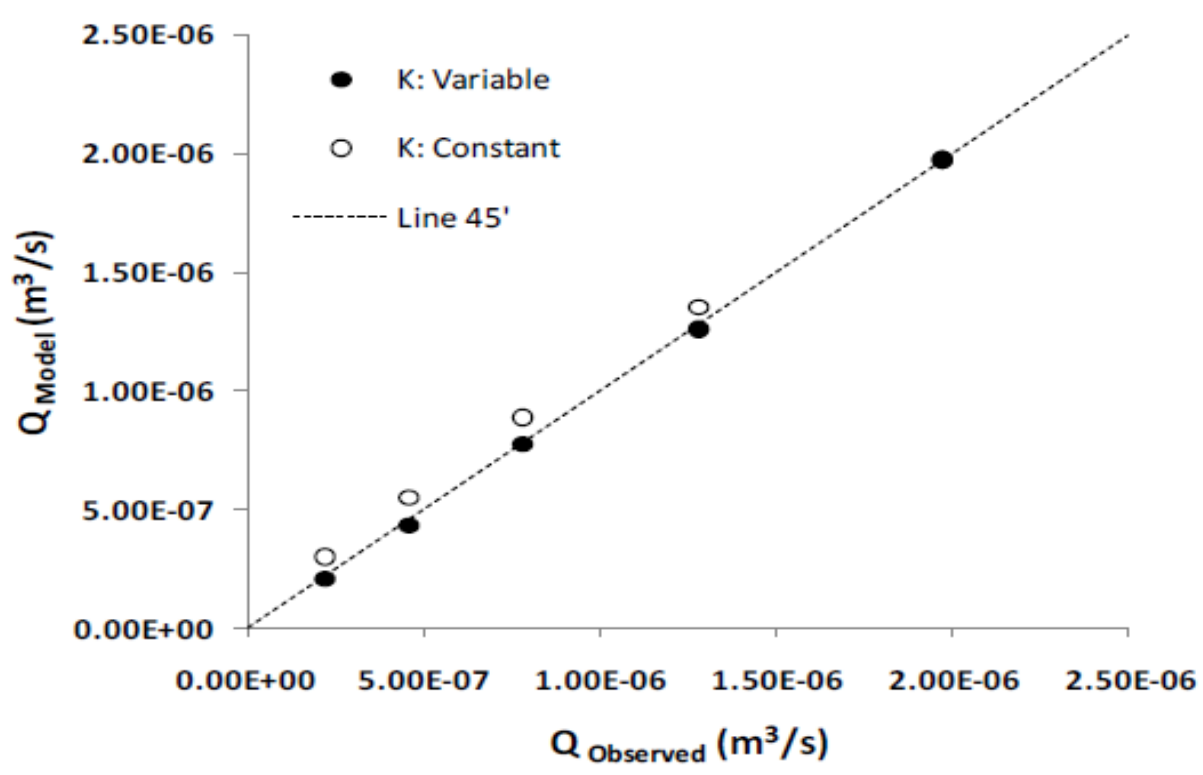

Figure 13. Comparison of leakage values from numerical analysis in two different conditions._Application of constant saturated hydraulic conductivity and hydraulic conductivity variable with_leakage values observed. 


\subsection{Unsteady Seepage}

Results of numerical analysis of unsteady state seepage flow with rapid drawdown in the reservoir water level from 60 to $15 \mathrm{~cm}$ showed that the drainage rate through the dam body for the application of saturated and unsaturated hydraulic conductivity is different. Investigations have shown that for unsaturated hydraulic conductivity, drainage rate is high and the decrease in pore water pressure is fast in this state (Figure 14). As can be seen, at the same times after the rapid drawdown, the water drainage of the body and the phreatic drawdown occur faster when applying the pore pressure.
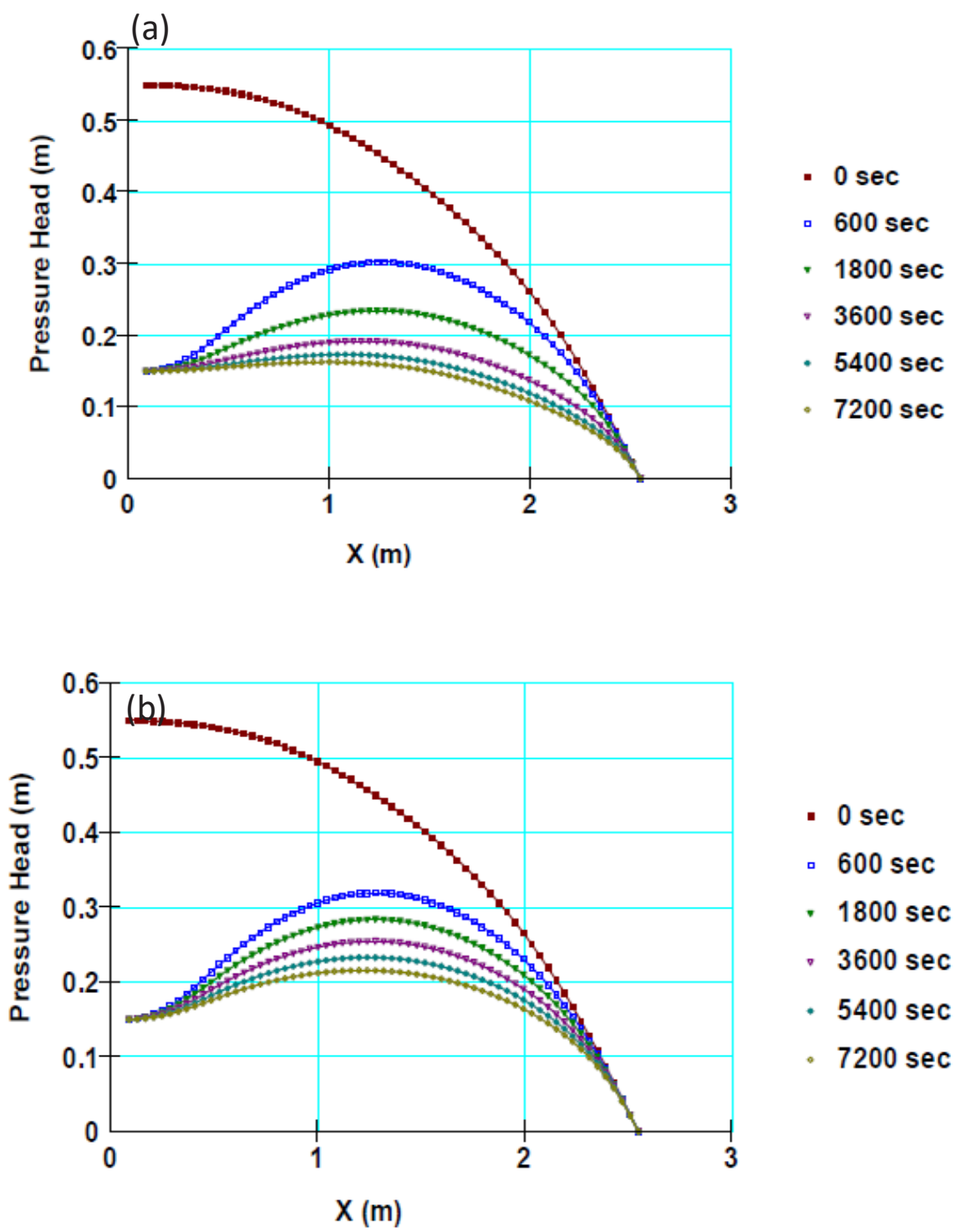

Figure 14. Changes in pore water pressure inside the dam body based on conductivity Constant saturated hydrocarbon (a) and unsaturated hydraulic conductivity (b).

Comparing the measured data after 30 minutes from the start of the water drawdown in the reservoir the same results have been obtained with what happened in the steady seepage flow. In these conditions, numerical results based on unsaturated hydraulic conductivity are more accurate and are consistent fairly well with measured data.

Figure 15 shows piezometric pressure variations based on the first row piezometers, which have 
more accurate results than upper row piezometers. In these situations (unsteady seepage flow) the difference between the measured data and the model results in the downstream of the dam body is increased. However, because of the slope of the phreatic surface in upstream and return flows due to the water drawdown, the difference between the measured data and the numerical results at the upstream sections is also significant. Although, the accuracy of the results of numerical analysis are high based on unsaturated hydraulic conductivity.

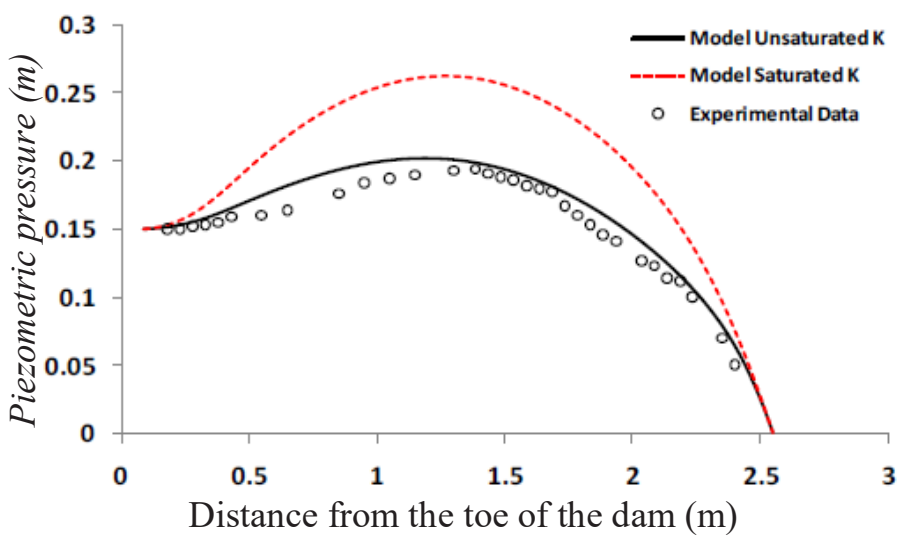

Figure 15. Piezometric pressure in non-permanent leak analysis 30 minutes after the drop in the reservoir's water level from a level of 60 to $15 \mathrm{~cm}$ in a piezometer: First row (lowest row(.

\section{CONCLUSIÓN}

The results of the experiments and analysis showed that the use of unsaturated hydraulic properties of the material forming the body of the dam is essential in the rapid drawdown of the water level, so that if a constant amount is used for the hydraulic conductivity of the material, the results of the rapid drawdown of water level will be far away the reality. In numerical modeling of this study, based on the finite element method, according to the number and type of selected elements, for both states of the application of fixed hydraulic conductivity and hydraulic conductivity as a function of the estimated saturation degree of the pore pressure, the results of numerical analysis were more than the observational data. Analysis of the difference between model and experimental data showed that with approaching the range of the phreatic line, the difference between experimental data and numerical analysis is increased. In addition, due to the slope of the phreatic line, the difference between numerical and observational data increases. This point was observed in both steady and unsteady seepage analysis, so that the maximum difference was observed for steady state seepage in downstream, which is associated with an increase in the slope of phreatic water level. In the unsteady seepage flow and the rapid drawdown of the water surface due to the seepage flow through the body in the downstream, the phreatic line slope was simultaneously directed towards the downstream of reservoir body face, causing a difference between the measured data and model results in both sides of the dam. This difference is significantly higher than the difference observed in the rapid drawdown in water level and steady seepage analysis.

Determining drainage rate of the dam body during unsteady state seepage analysis showed that the rate of drawdown in water surface in the dam body for applying the steady hydraulic conductivity is much slower than that of the unsaturated hydraulic conductivity. This is an important step in the stability analysis, in order to increase the confidence coefficient. However, it may increase the dimensions of the dam body. 


\section{REFERENCES}

1. Sun D. M., Zhu Y. M. \& Zhang M. J. 2007 Waterair two-phase flow model for numerical analysis of rainfall infiltration. Journal of Hydraulic Engineering, 38(2), 150-156.

2. Ataie-Ashtiani B., Volker R. E. \& Lockington D. A. 1999 Numerical and experimental study of seepage in unconfined aquifers with a periodic boundary condition. Journal of Hydrology, 222(1-4), 165-184. DOI: 10.1016/S00221694(99)00105-5.

3. Bardet J. P. \& Tobita T. 2002 A practical method for solving free surface seepage problems. Journal of Computer and Geotechnics, 29(6), 451-475. DOI: 10.1016/S0266-352X(02)00003-4.

4. Ji C. N., Wang Y.Z. \& Shi Y. 2005 Application of modified EP method in steady seepage analysis. Journal of Computer and Geotechnics, 32(1), 27-35. DOI: 10.1016/j.compgeo.2004.11.006.

5. NanshengL., Bo T.\&Lihui X. 2015 Slope stability analysis of earth-rockfill dams using MGA and UST. Journal of Computational Engineering, 2015. DOI: $10.1155 / 2015 / 895142$.

6. Kahot z., Dkiouak R. \& Khamlichi A. 2019 Reliability analysis of slope stability in earthen dams following rapid drawdown. International Review of Applied Sciences and Engineering, 10(1), 101-112. DOI: 10.1556/1848.2018.0011.

7. Calamak M \& Yanmaz A. M. 2014 Probabilistic Assessment of slope stability for earth-fill dams having random soil parameters. 5th International Symposium on Hydraulic Structures. 25-27 June, Brisbane, Australia. DOI: 10.14264/ uql.2014.16.

8. Fu J. \& Jin S. 2009 A study on unsteady seepage flow through dam. Journal of Hydrodynamics, 21 (4), 499-504. DOI: 10.1016/S10016058(08)60176-6.

9. Ghanbarian-Alavijeh B., Liaghat A., Huang G. H. \& Van Genuchten M. Th. 2010 Estimation of the van genuchten soil water retention properties from soil textural data. Pedosphere, 20 (4), 456465. DOI: 10.1016/S1002-0160(10)60035-5.

10. Zhang Y. L., Chen R. \& Li J. H. 2011 Evaluating the accuracy of unsaturated hydraulic conductivity determined by instantaneous profile method. In Proceedings of the 5th Asia-Pacific Conference on Unsaturated Soils, Kasetsart University, Pattaya, Thailand.

11. Reynolds W. D., Gregorich E. G. \& Curnoe W. E. 1995 Characterisation of water transmission properties in tilled and untilled soils using tension infiltrometers. Soil Tillage Research, 33(2), 117-131.

12. White I., Sully M. J. \& Perroux K. M. 1993 Measurement of surface-soil hydraulic properties: disk permeameters, tension infiltrometers and other techniques. In: Topp, G.C., Reynolds, W.D., Green, R.E. (Eds.), Advances in Measurement of Soil Physical Properties: Bringing Theory into Practice. Soil Science Society of America, Special Publication, 30, 69-104.

13. Sedghi-Asl M. H., Rahimi H. \& Khaleghi H. 2010 Experimental analysis of seepage flow under coastal dikes. Experimental Techniques, 34(4), 49-54. DOI:10.1111/j.17471567.2009.00562.x.

14. Logsdon S. D. \& Jaynes D. B. 1993 Methodology for determining hydraulic conductivity with tension infiltrometers. Soil Science Society of America Journal, 57(6), 1426-1431. DOI : 10.2136/sssaj1993.03615995005700060005x

15. Wooding R. A. 1968 Steady infiltration from a circular shallow circular pond. Water Resources Research, 4(6), 1259-1273. DOI: 10.1029/ WR004i006p01259.

16. Gardner W. R. 1958 Some steady-state solutions of unsaturated moisture flow equations with application to evaporation from a water table. Soil Sciences. 85(4), 228-232. 